\title{
A Suggestion for a New E-Governance System in the Wheat Supply Chain Management ${ }^{\#}$
}

\author{
Abdullah Oktay Dündar*1, Kenan Peker ${ }^{2}$, Mahmut Tekin $^{3}$, Mehmet Akif Şahman ${ }^{4}$, Mustafa Büber ${ }^{5}$ \\ Accepted $3^{\text {rd }}$ September 2016
}

\begin{abstract}
Previously in Turkey, there have been no information systems used by buyers and suppliers in the wheat supply process. In general, the supply process has previously been accomplished through personal meetings or through the stock market. After loading their wheat on vehicles, farmers take the wheat to potential buyers (e.g. flour mills, merchants, stock market, Agricultural Products Office [APO]). The buyers evaluate the wheat using laboratory facilities, or by observation, and offer a price to the farmers. If there is a deal, the sale is realized. If there is no deal, the farmers take the wheat to other potential buyers and follow the same process again. This leads to unnecessary transportation, and an unnecessary increase in costs.
\end{abstract}

This study proposes a wheat supply e-governance system to eliminate unnecessary transportation, and create a new communication channel between buyers (flour mills as the end buyers) and suppliers (farmers). This system will enable a reduction in the length of the supply chain, building faster communication between the members of the supply network, and will reduce the costs of buying and carrying wheat. In addition, the agricultural consultancy system will be operated more effectively, and farmers will be able to learn about their own analysis results from the system.

Keywords: Agricultural Supply Chain Management, Grain Supply Chain Management, Wheat Supply, E-Governance, Information and Communications Technologies

\section{Introduction}

In today's information age and globally competitive market environment, the effective integration of the complex network structure of supply chain management depends on the fact that information flows are fast, efficient and controllable. With the widespread penetration of technologies such as the internet, barcode systems and mobile devices all over the world, the place for information technology in the supply chain network designs becomes viable.

Information and communications technology (ICT) is any device, tool, software or application that allows data collection and exchange through mutual interaction or transfer. Information and communications technology is a broad structure that includes every element in the supply chain from radio to satellite, from mobile telephony to computer networks, from electronic money transfer to the global supply chain and tracking a product in motion [1]. Information and communication technologies have begun to be used, particularly in rural areas, for the development of the agriculture and education sectors in order to be a venue for global markets. Over time, information technology has become widespread in smaller-scale enterprises [2].

In supply chain management, the role of information technology should not be evaluated only as a simple communication problem solver. In addition to the continuous information flow of

${ }^{1}$ Akören Vocational School, Selçuk University, Konya/Turkey

${ }^{2}$ Faculty of Economics and Administrative Sciences, Firat University,

Elazı̆̆/Turkey

${ }^{3}$ Faculty of Economics and Administrative Sciences, Selçuk University, Konya/Turkey

${ }^{4}$ Faculty of Technology, Selçuk University, Konya/Turkey

${ }^{5}$ Doğanhisar Vocational School, Selçuk University, Konya/Turkey

* Corresponding Author: Email: aodundar@selcuk.edu.tr

Note: This paper has been presented at the International Conference on Advanced Technology\&Sciences (ICAT'16) held in Rome (Italy), November 23-25, 2016 information technology, it also enables the planning of business activities and the structuring of strategic decisions [3].

\section{Electronic Supply Chain Management}

With the widespread use of the internet all over the world in the 1990s, enterprises in supply chain management have started to carry out buyer-supplier relations through internet-based software. In supply chain management, the internet has found an important place in many different fields, including raw material procurement, product ordering, product advertisement, product sales, warehouse and stock management, distribution and customer service.

Different electronic network designs can be created for different purposes in electronic supply chain management. An internetbased system designed for the purchase of raw materials and semi-finished products by the enterprise can be called Eprocurement, while a system created to deliver final products to the customers or final customers can be called E-distribution, and a system that provides the integration of information flow and communication to all services from the government to the consumer, or from the government to the enterprises, can be called e-governance.

E-procurement can be defined as the making of all corporate purchases using internet-based systems. It is essential for the enterprises in order to compete in today's highly competitive market conditions to supply the highest quality product at the cheapest cost and in the shortest time to the market. In order to reach these targets, the buyer-supplier communication needs to be done using information and communication technology techniques. Today, business to business (B2B) has become an important trend with the advantages it presents, and its growing 
development potential [4].

E-procurement will provide the enterprise with advantages including reducing the administrative costs, the supply-demand cycle times, the raw material costs, the warehouse and inventory costs, and provide easier access to business partners and wider markets for products [5]. It has even been said that the concept of e-procurement should be broadly assessed to include the e-design concept of enhancing the characteristics of the entire supply chain, including supplier and buyer performance [6].

The most comprehensive application of electronic supply chain management is the e-governance system, which enables the integration of all government services, information flow and communication to the consumers. In e-governance, the government also participates in electronic supply chain management as a party, and this participation provides extra advantages including increasing the buyer-supplier communication, reduction of costs, increasing the quality of the services provided as well as providing control of additional costs and services, transparency, fraud and corruption [7].

\section{Use of Information and Communication Technologies in the Agriculture Sector}

Food supply chains have their own unique structures. Processes ranging from the production of vegetables or animal products to the table of the final customer can be described as two main food supply chains [8].

The supply chain for fresh agricultural products: supply chains that cover the management of products including fresh vegetables, fruits and flowers. This supply chain may include cultivators, wholesalers, importers, exporters, retailers, vendors and tenders. The main process includes collection, transportation, storage, packaging, transfer and especially the sale of products.

The supply chain for processed products: is the supply chain that covers the management of certain processed products including desserts, pastry and canned foods. In this supply chain, management of processes such as protection, storage and shelf life become more important.

The most critical decision for industrial enterprises in the agricultural area is to provide the best flow of the correct, high quality food to be used as raw material to the farm. There are critical decision stages, including the transport of food to the farm under appropriate conditions, storage under appropriate conditions after transport and the shelf life of the food included in the production process. Today, the foods need to be good quality and be reliably supplied because customers are becoming more conscious in terms of food safety. In terms of quality and safety, businesses must have in-house quality control systems as well as quality food monitoring and follow-up systems [8].

Considering the raw material producers, other critical questions come to mind:

-What is the best sowing strategy?

-Where can I get the best and most efficient seed?

-What is the most fertile soil?

-Where can I sell my product at the highest price on the market?

-How can I get my products to buyers at the lowest cost?

-How can I benefit from government and private enterprise support?

It is possible to replicate these and similar questions, and the correct answers to the questions depend on many factors. Many variables, from geographical region to seasonal changes, from production to market and supply to demand, influence the decision stages of this chain [1].
In light of these requirements, the food supply chain needs to be handled as a whole, from the harvest to the table of the consumer. Electronic food supply chain management has very specific functions to carry out. The food supply chain has different information and communication technologies designed for different decision purposes, providing information flow about buyer-supplier interactions and environmental factors.[8].

Auernhammer emphasized the importance of traceability of harvested crops in the supply chain and suggested that the use of high-technology electronic devices would provide valuable information for the effective documentation and monitoring of all the processes that are involved in production [9]. Ruiz-Garcia defined an internet-based food monitoring and tracking system model to increase the visibility of agricultural products. Sensitive agricultural decisions, information recorded during transport and distribution were used to test the prototype model. This system provides full traceability compatible with all of the standards for system monitoring and follow-up. This software architecture offers new possibilities for traceability, control and management using a series of standards. The software architecture of the monitoring and tracking system is shown below [10].

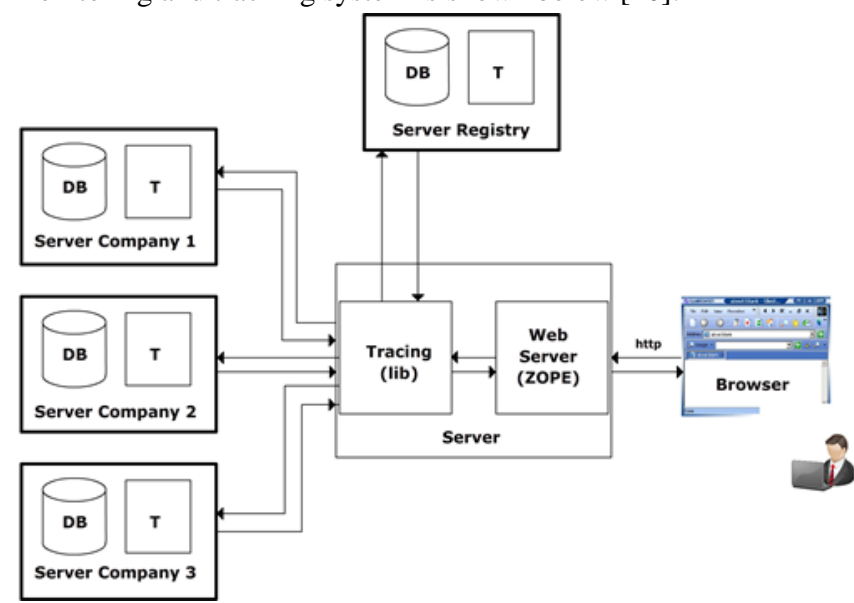

Figure 1. Architecture of Traceability System.

The Preagro research project aimed to establish a site-specific crop production management system aimed at increasing agricultural yield and improving environmental benefits. Accordingly, the "agricultural data-processing service" has been defined, and it has been shown that the information flow related to raw material production can be improved with similar systems [11] [12].

On the other hand, supply chain management activities should not be based solely on the principle of transparency and sharing of information. Proper use of resources and co-ordination of decision policies are very important, in addition to effective information flow. In general, the concept of electronic supply chain management, or e-business, needs to be evaluated in two ways [13].

To increase the efficacy and efficiency of the existing supply chain, this concept should be understood as an electronic sharing of demand, inventory and production data between enterprises in the value chain, and improving the entire value chain at this point. The visibility of the information should be coordinated with the objectives, performance indicators and critical decisions of the supply chain. This will ensure that the efficacy and efficiency of the system will be improved by eliminating disadvantages such as uncertainty in decision-making, uncertainty of inventory levels and time penalties.

Creating new business models for dynamic supply chains: This e- 
business concept redefines the business roles of enterprises and creates a new supply chain structure. The new business lines required by the market dynamism and new business relationships are rearranged dynamically as needed. In this potentially identified new business model, suppliers will be selected from global electronic markets as needed.

Standardized technologies containing a common language should be used to carry out these complex and integrated processes within the food supply chain. Web-based systems designed for data processing, storage and distribution offer very flexible opportunities for information transport, mutual sharing and functionality of information. Web-based systems can also connect different data sources [14].

The use of information and communication technologies also increases the communication between the buyer in the city and the supplier in the rural area. Thus, co-evaluation resources such as roads, communication tools and electricity will lead to efficient food mobility between rural areas and cities [1]. Additionally, web-based information and communication technologies will contribute to the formation of a global market by removing borders.

Another consequence of the global market concept is the involvement of more than one government in the commercial process and the integration of these governments in separate commercial legal arrangements. One of the responsibilities of governments to their citizens is to ensure that good quality products are delivered to the citizens with price transparency. The government determines price policies in different sectors, controls the quality of products and participates in the regulation of buyer-supplier relations. In supply chain management, the government is involved in the process of food quality and safetyrelated process in the context of investigating whether it is a threat to public health.

\section{Literature Research}

Mangina and Vlachos, in their study, developed an intelligent food supply chain model that enables the supply chain to work effectively. The aim of the study was to show that the intelligent agent and multiple agent technologies can optimize the food supply chain. In this study, the internet technologies of the supply chain were investigated, and the distribution network of intelligent agents for the brewing supply chain were modelled. With the developed model, it has been shown that agents can be useful in solving the problem of supplying beverages, reducing inventory and increasing communication [15].

Szilagyi et al., in their study, reviewed the literature on agricultural applications of mobile devices [16].

Schulze et al., in their study, developed a performance measure to evaluate the agricultural companies' own supply chains and relationships. The researchers reported that producers using agricultural raw materials often have to deal with many small farmers and that the studies showed that satisfaction, trust and commitment have become important in the relationship between producers and farmers. The model developed in the study was tested in the context of establishing and maintaining relationships in the milk chain in Germany. It has been stated that the orientation of the farmer is surprisingly more important than the product prices. It has been reported that it is important for producers to understand farmers' problems and to communicate better. Some suggestions have been made to the producers in light of the findings of the study [17].

Van der Vorst et al., in their study, developed a simulation to solve the problems of the food supply chain and to increase its sustainability. The increase in customer demand, changes in quality values and unresponsive requirements are major problems in the food supply chain. The developed simulation is used in decision support systems. It was necessary to be flexible enough to take account of uncertainties in transportation. A combined approach called ALADINTM was proposed in this study. Logistics, sustainability and food quality analysis can be carried out using this approach. In the simulation model, food quality and sustainability are discrete. It has been shown that the structure was useful in case studies [18].

Demokaan, in their study, gave information about global practices by drawing a theoretical framework describing egovernance. Developments in agricultural areas, by increasing the awareness of villagers in rural areas of India and their access to the information, have made it possible for those concerned to acquire the registers of farmed and rented land records of the farmers by putting the land registers online [19].

Iashgarara et al., in their study, have shown that information and communication technologies have an important role in the marketing of agricultural products by increasing the speed of information delivery [20].

The study of Wolfert and Kempenaar provided information on the role of information and communication technologies for future agricultural practices, and the role of agriculture for future information and communication technologies [21].

Sani, in their study, gave information about the use of information technologies in agriculture, the use of information technology in agricultural education management and the application of information technology in agriculture, explaining why information technologies should be used [22].

The short communique "ICT Applications and Agricultural Input Supply Companies: Highlights From Africa", published by the United States Agency for International Development (USAID), presented the results of a study conducted to determine and document the information and communication technologies (ICT) used by the companies providing agricultural inputs in Africa to better manage the distribution network, to provide important products, services, information and technical support to farmer customers and to share sample applications [23].

\section{Wheat Procurement E-Governance System}

There is no information system used between the buyer and the supplier in the wheat supply process in Turkey. The procurement process is usually through face-to-face interviews or through stock markets. The farmers load the wheat they produce onto vehicles and then take it to potential buyers (flour factories, tradesmen, stock markets, TMO (Soil Products Office)). After the buyer evaluates the wheat by means of laboratory facilities or observation, the farmer proposes the price for wheat. If an agreement is reached, the sale is realized. However, if an agreement cannot be reached, the farmer takes the wheat to another potential buyer and the same process starts again. In this case, unnecessary transportations occur and transportation costs increase. A wheat supply e-governance system has been developed to remove unnecessary duplication of effort and create a new communication channel between the buyer and the supplier.

\subsection{Elements and Structure of E-Governance System}

The e-governance system that we have developed consists of 4 types of members and a system administrator. System members are wheat-producing farmers, agriculture consultants, wheat buyers, intermediate warehouses and system administrators. The 
intermediate storage can be the factories' own warehouses, or they can be the TMO warehouses or other licensed warehouses. The system administrator is defined as the university where the system is installed.

The system is a content management system written in open source coding (Content Management System-CMS). The software is PHP (Hypertext Preprocessor-Personal Home Page). PHP is a server-side, scripting and programming language produced for the internet, which has very wide-ranging use for general purposes that can be embedded in HTML [24]. PHP is preferred because it is the most widely used open source coding language. MySql is used as a database on the system. MySql is preferred because it's free, fast querying and compatible with PHP. The components of the wheat supply e-governance system we have developed are shown in Figure 2.

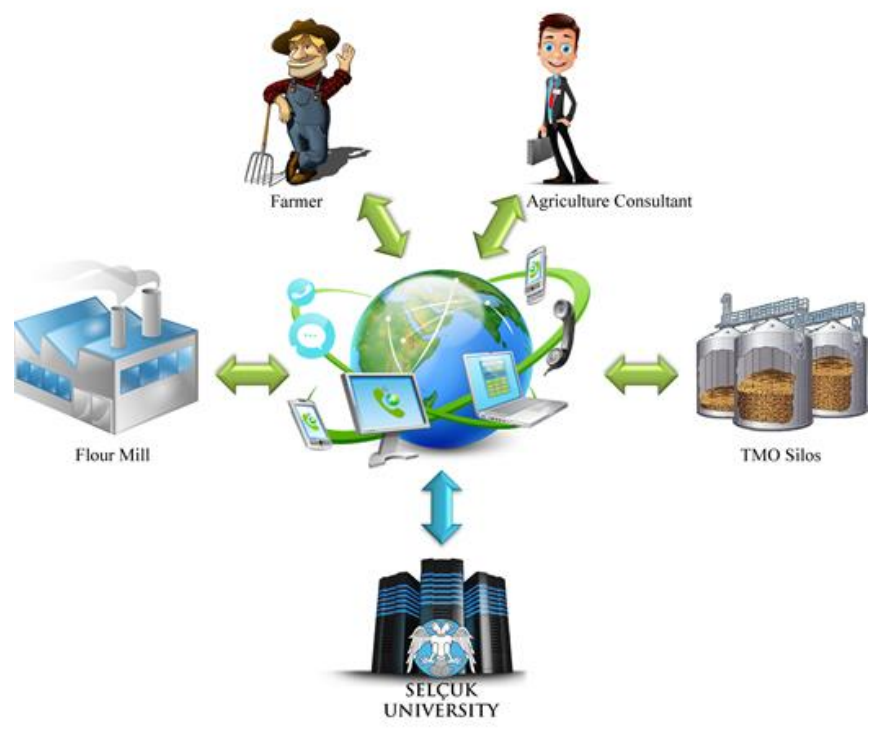

Figure 2. Wheat Procurement E-Governance System Components

Five separate authorization levels have been identified in the wheat supply e-governance system. Authorization allows members to perform transactions only with respect to themselves; access to information, change of information and deletion are prevented in areas outside their authority. The members can be connected to the system using any hardware (computer, tablet, hand-held terminal, mobile phone) via the internet. The members who are added to the system are first registered in the membership table. In the member's table, the member type (farmer, factory, agriculture consultant and warehouses (silos)) is defined and associated with other tables according to their authority level. With this authorization, the member can see the information sent to him, and he can respond to the requests from the system.

\subsection{Operation Algorithm of E-Governance System}

For the system to function, farmers need to send the wheat sample to the factory or agriculture consultants. The samples are analysed using the mobile NIR (Near Infrared Reflectance) device in the factory laboratory or by the agriculture consultant, and the results are uploaded to the system via the internet. The factory evaluates the analysis results and makes a price offer to the farmer. The farmer evaluates the offer and the process ends if the farmer does not accept that offer (REJECT). If the farmer accepts the offer, an agreement is reached on the price. In this case, the factory will notify the delivery address for the wheat. The wheat is delivered either to the factory or to the warehouse designated by the factory. If it is delivered to the factory (orange line) the farmer brings the wheat to the factory for analysis. This process is necessary to confirm whether the delivered wheat is the same as the sample. If the analysis results are different, the factory may reject the wheat purchase (REJECT).

If the wheat is going to be delivered to the warehouse (green line), the farmer brings the wheat to the warehouse. If the analysis results are not consistent, the warehouse may not accept the wheat purchase (REJECT). If the analysis results are consistent, the warehouse accepts the wheat purchase, classifies the wheat according to the previously determined criteria, according to the analysis results, and transfers the wheat to the related silo.

After this stage, the factory may withdraw the wheat from the reservoir at a later date. The factory sends the amount of goods that is going to be taken from the warehouse with date information. The warehouse transports the wheat to the factory in accordance with this information. The factory makes the analysis of the incoming wheat (from the farmers and the warehouses) and if the results are inconsistent with the information in the system, it may not accept the wheat (REJECT). If the analysis of wheat from both the farmers and the warehouses is compatible with the information in the system, the factory accepts the purchase of wheat (blue line). The factory transfers the wheat to the silo and the process is finalized. The algorithm for the developed wheat procurement e-governance system is explained as Figure 3.

\section{Conclusion}

With this e-governance system, a system infrastructure has been developed in which all stakeholders can be involved in the wheat supply network. With this system, cooperation between universities, industry, farmers and the TMO will be enabled. The farmers will be able to sell directly to the buyer without transporting their products between flour factories. With this system, it is also possible to classify the wheat. In addition, it has contributed to the functioning of the agricultural counseling system implemented by the Ministry of Agriculture. The system quality values can be used by the agricultural incentive system to evaluate the performance of the farmers and be applied to an incentive system that rewards quality. Stakeholders (traders, farming chambers, research centers, farmers' cooperatives, ministry of agriculture, etc.) related to the wheat supply process can be easily added to the system if needed.

For future studies, we suggest:

- Carrying out studies on the development of different modules that will enable the implementation of the agricultural consultancy mechanism through the e-governance system

- An investigation on what the necessary legal arrangements should be if the E-governance system is implemented by the ministry.

\section{Acknowledgements}

This study is a part of the research which is founded by the Ministry of Science, Industry and Technology as SANTEZ project No: 0509.STZ.2013-2 for a Ph.D. thesis. 


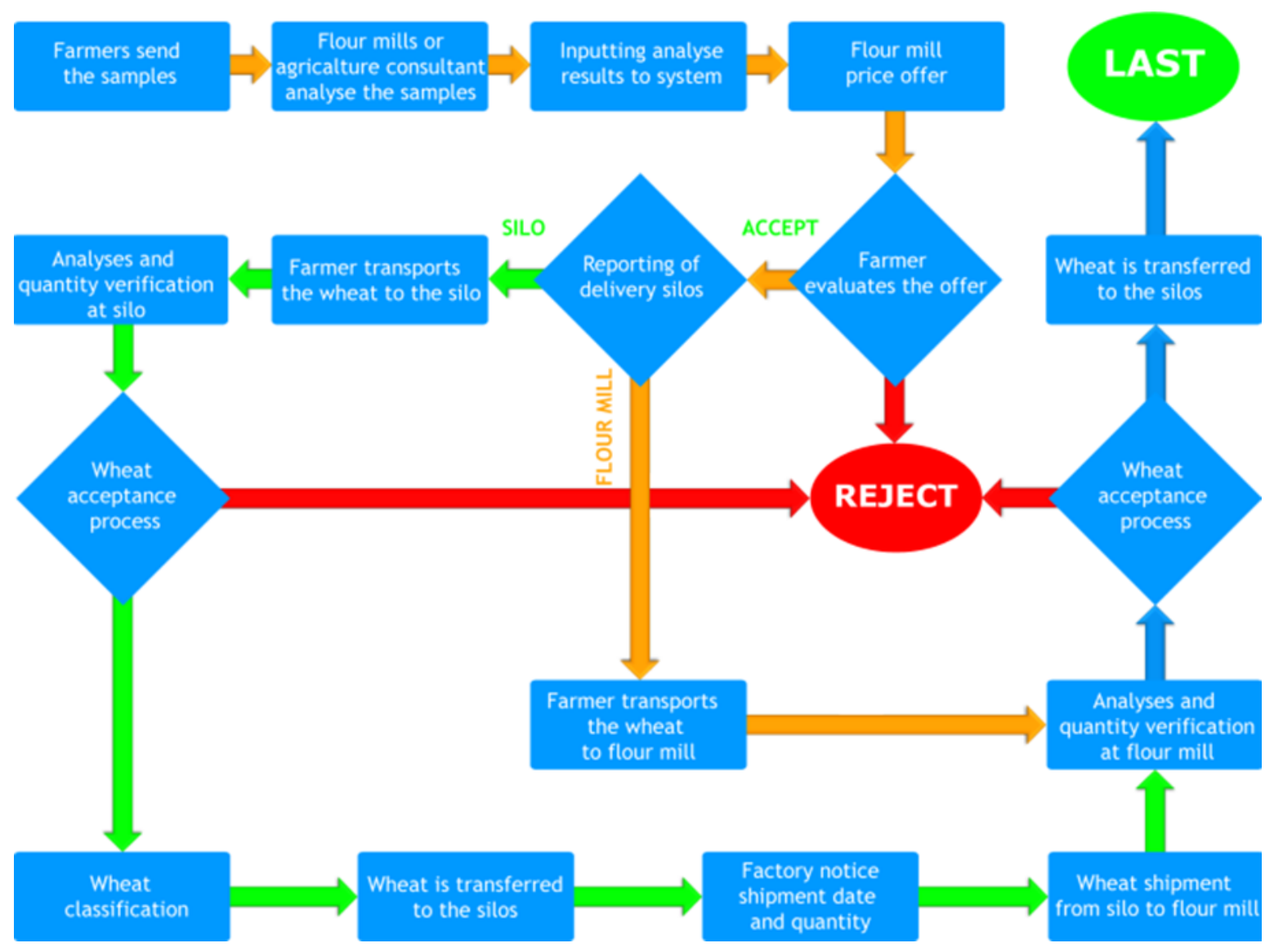

Figure 3. Operation Algorithm of Wheat Supply E-Governance System.

\section{References}

[1] World Bank (2011)" ICT in Agriculture - Connecting Smallholders to Knowledge, Networks, and Institutions" Report No: 64605, Washington

[2] Grimes, S. (1992). Exploiting information and communication technologies for rural development. Journal of Rural Studies, 8 (3), 269- 278.

[3] Adewole, A (2005), "Developing a Strategic Framework for Efficient and Effective Optimisation of Information in the Supply Chains of the UK Clothing Manufacture Industry", Supply Chain Management:An International Journal, Vol:10, Issue:5.

[4] McAfee, A. (2000). The napsterization of B2B. Harvard Business Review,78(6), 18-19.

[5] Güleş, H.K., Paksoy T., Bülbül H., Özceylan E.(2012)”" Tedarik Zinciri Yönetimi - Stratejik Planlama, Modelleme ve Optimizasyon" (Expanded Edition 2) Gazi Kitapevi, Ankara

[6] Presutti, W. D. (2003). Supply management and eprocurement: creating value added in the supply chain. Industrial marketing management, 32(3), 219-226.

[7] Singh, A. K., ve Sahu, R. (2008). Integrating Internet, telephones, and call centers for delivering better quality egovernance to all citizens. Government Information Quarterly, 25(3), 477-490.

[8] Van der Vorst, J. G., Van Dongen, S., Nouguier, S., and Hilhorst, R. (2002). E-business initiatives in food supply chains; definition and typology of electronic business models. International Journal of Logistics, 5(2), 119-138.

[9] Auernhammer, H. (2002). The role of mechatronics in crop product traceability. Agricultural Engineering International: The CIGR Journal of Scientific Research and Development.
Invited overview paper (Vol. IV, October 2002). Presented at the Club of Bologna meeting, July 27, 2002, Chicago, IL, USA

[10] Ruiz-Garcia, L., Steinberger, G., Rothmund, M. (2010). A model and prototype implementation for tracking and tracing agricultural batch products along the food chain. Food Control, 21(2), 112-121.

[11] Steinberger, G., Rothmund, M., Auernhammer, H., (2006). Agricultural process data service (APDS). In World congress agricultural engineering for a better world. Bonn 3-7.9.2006 Bonn, Book of abstracts. Düsseldorf: VDIVerlag 2006, pp. 271-272. ISBN: 3-18-091958-2.

[12] Preagro, (2008). Collaborative Research Project Preagro. www.preagro.de date of access: 05.10.2015.

[13] Janssen, M., Sol, H. G. (2000). Evaluating the role of intermediaries in the electronic value chain. Internet Research, 10(5), 406-417.

[14] Curbera, F., Khalaf, R., Mukhi, N., Tai, S., Weerawarana, S. (2003). The next step in web services. Communications of the Association for Computing Machinery, 46, 29-34.

[15] Mangina E, Vlachos IP, (2005). The changing role of information technology in food and beverage logistics management: beverage network optimisation using intelligent agent technology. Journal of Food Engineering, 70, 3, 403-20.

[16] Szilagyi R., Herdon M., Lengyel P., .(2005) "Agricultural application development for mobile devices," http://www.avacongress.net/ava2005 /presentations /agrarin formatika/2.pdf

[17] Schulze B, Wocken C, Spiller A, (2006). Relationship quality in agri-food chains: Supplier management in the German pork and dairy sector. Journal on Chain and Network Science, 6, 1, 55-68. 
[18] Van der Vorst JG, Tromp S-O, Zee D-Jvd, (2009). Simulation modelling for food supply chain redesign; integrated decision making on product quality, sustainability and logistics. International Journal of Production Research, 47, 23, 6611-31.

[19] Demokaan D. (2010) "Yönetişimde Yeni Bir Boyut: EYönetişim”, Türk İdare Dergisi, Sayı: 466, 65-94,

[20] Iashgarara F., Mohammadi R., Najafabadi M.O. (2011) "Challenges And Implications of ICT Application For Improving The Marketing Of Agricultural Products At Garmsar City, Iran” Agricultural Science Digest, 31 (3) : $161-166$,

[21] Wolfert, J., Kempenaar, C.(2012)" The role of ICT for Future Agriculture and the role of Agriculture for Future
ICT" Proceedings of the 6th International Weed Science Congress, Hangzhou, China. 1 - 3.

[22] Sani B. (2013) "E-Agriculture Development by Information and Communication Technology (ICT) Application" AWER Procedia Information Technology \& Computer Science Vol 03 1330-1334

[23] USAID (United States Agency for International Development) (2013) "ICT Applications And Agricultural Input Supply Companies: Highlights From Africa" Briefing Paper.

[24] https://tr.wikipedia.org/wiki /PHP, Access Date: 01.04.2016 